\title{
Interferon alpha therapy for hepatitis C: treatment completion and response rates among patients with substance use disorders Marilyn S Huckans* ${ }^{\dagger 1,2,3}$, Jennifer M Loftis ${ }^{\dagger 1,2,3,6}$, Aaron D Blackwell ${ }^{1,2,7}$, Alex Linke ${ }^{1,2}$ and Peter Hauser $1,2,3,4,5,6$
}

\begin{abstract}
Address: ${ }^{1}$ Northwest Hepatitis C Resource Center, Portland VA Medical Center, Portland, USA, ${ }^{2}$ Behavioral Health \& Clinical Neurosciences Division, Portland VA Medical Center, Portland, USA, ${ }^{3}$ Department of Psychiatry, Oregon Health \& Science University, Portland, USA, ${ }^{4}$ Department of Behavioral Neurosciences, Oregon Health \& Science University, Portland, USA, ${ }^{5}$ Department of Internal Medicine, Oregon Health \& Science University, Portland, USA, ${ }^{6}$ J.E.N.S. Laboratory, Portland VA Medical Center, Portland, USA and ${ }^{7}$ Department of Anthropology, University of Oregon, Eugene, USA
\end{abstract}

Email: Marilyn S Huckans* - marilyn.huckans@va.gov; Jennifer M Loftis - loftisj@ohsu.edu; Aaron D Blackwell - ablackwe@uoregon.edu; Alex Linke - alex.linke@va.gov; Peter Hauser - peter.hauser2@va.gov

* Corresponding author †Equal contributors

Published: 12 January 2007

Substance Abuse Treatment, Prevention, and Policy 2007, 2:4 doi:10.1 186/1747-597X-2-

4

This article is available from: http://www.substanceabusepolicy.com/content/2/I/4

(c) 2007 Huckans et al; licensee BioMed Central Ltd.

This is an Open Access article distributed under the terms of the Creative Commons Attribution License (http://creativecommons.org/licenses/by/2.0), which permits unrestricted use, distribution, and reproduction in any medium, provided the original work is properly cited.
Received: 16 December 2005

Accepted: 12 January 2007

\begin{abstract}
Background: Individuals with substance use disorders (SUDs) are at increased risk for hepatitis $\mathrm{C}$ viral infection (HCV), and few studies have explored their treatment responses empirically. The objective of this study was to assess interferon alpha therapy (IFN) completion and response rates among patients with HCV who had a history of comorbid SUDs. More data is needed to inform treatment strategies and guidelines for these patients. Using a medical record database, information was retrospectively collected on 307,437 veterans seen in the Veterans Integrated Service Network 20 (VISN 20) of the Veterans Healthcare Administration (VHA) between 1998 and 2003. For patients treated with any type of IFN (including regular or pegylated IFN) or combination therapy (IFN and ribavirin) who had a known HCV genotype, IFN completion and response rates were compared among patients with a history of SUD (SUD+ Group) and patients without a history of SUD (SUD- Group).

Results: Odds ratio analyses revealed that compared with the SUD- Group, the SUD+ Group was equally likely to complete IFN therapy if they had genotypes 2 and $3(73.1 \%$ vs. 68.0\%), and if they had genotypes I and 4 (39.5\% vs. 39.9\%). Within the sample of all patients who began IFN therapy, the SUD- and SUD+ groups were similarly likely to achieve an end of treatment response (genotypes 2 and 3, 52.8\% vs. 54.3\%; genotypes I and 4, $24.5 \%$ vs. $24.8 \%$ ) and a sustained viral response (genotypes 2 and 3, $42.6 \%$ vs. $41.1 \%$; genotypes I and 4 : $16.0 \%$ vs. $22.3 \%$ ).

Conclusion: Individuals with and without a history of SUD responded to antiviral therapy for HCV at similar rates. Collectively, these findings suggest that patients who have co-morbid SUD and HCV diagnoses can successfully complete a course of antiviral therapy.
\end{abstract}




\section{Background}

Patients with co-morbid substance use disorders (SUDs) and psychiatric disorders are at increased risk for hepatitis $\mathrm{C}$ virus (HCV) infection and constitute the vast majority of persons with chronic HCV [1-4]. HCV occurs in up to $90 \%$ of injection drug users [5]. Relative to the general population, the incidence of HCV is also high among non-injection drug users. In a sample of over 700 noninjection drug users (heroin, cocaine, or crack) the prevalence of HCV ranged from $5 \%$ to $29 \%$, depending on age, gender, study location, and drugs used [6]. To date, few studies have been completed that examine whether ongoing injection or non-injection drug use affects the course of HCV infection.

Currently, standard treatment for HCV is combination therapy with pegylated interferon alpha (IFN) and ribavirin $[7,8]$. However, in addition to its antiviral effects, IFNbased therapies are also associated with a number of adverse effects, in particular neuropsychiatric side effects [9]. Studies suggest that as many as $75 \%$ of patients on IFN report one or more psychiatric side effects including depression, anxiety, insomnia, and impaired concentration $[10,11]$, and approximately $20 \%-30 \%$ meet criteria for IFN-induced major depressive disorder $[12,13]$. Healthcare providers have been reluctant to treat adults with co-morbid SUDs because of concerns that these neuropsychiatric side effects may increase risk of relapse [14]. Although there is little empirical data, clinicians may also be concerned that individuals with current or active SUDs are more likely to be non-compliant with treatment, thus jeopardizing efficacy [15]. Most physicians withhold antiviral therapy from HCV-infected alcohol or drug users until patients have maintained abstinence for a period of at least six months [16].

As a result of these attitudes, a disproportionately low number of patients with SUDs have participated in clinical trials or have received antiviral therapy for HCV [17]. In one prospective study of 100 patients who were screened for psychiatric illness, SUDs, or serious medical illness, 68 were found ineligible for IFN therapy due to the presence of at least one of these disorders [18]. Similarly, in another study of 557 patients referred to an HCV clinic, $21 \%$ were excluded for psychiatric disorders, $14 \%$ for current alcohol abuse, and 3.5\% for current injection drug use [19]. One large retrospective study conducted in France found that almost one in six patients with HCV did not receive on-going health care following the diagnosis of chronic HCV [20]. Close to $60 \%$ of the patients who did not receive follow-up care belonged to the "high-risk lifestyle group, " which included patients with a history of nasal or intravenous drug use and $22.8 \%$ of this group were patients with current alcohol abuse (defined as $>50$ $\mathrm{g} /$ day) [20]. These data suggest that initial barriers to treat- ment may be related to clinician's negative attitudes about SUDs.

There is a lack of evidence that a history of SUDs preclude treatment tolerance or efficacy. Although sample sizes are small, several recent studies have demonstrated adequate viral response rates in injection drug users still actively using [21-24]. Based on a recent review of 10 clinical trials published between 2001 and 2004 concerning antiviral therapy in substance users, the sustained viral response (SVR) and adherence rates were not different from nondrug users with HCV [25]. Other studies suggest that while heavy drinking (> 70 to $80 \mathrm{~g}$ /day) has been associated with poor SVR, individuals with a history of mild to moderate alcohol use who abstain for a period prior to and during IFN therapy have SVR rates that are similar to those found in patients without a history of alcohol abuse [2630]. Less is known about mild to moderate alcohol use during treatment, and larger sample size studies are still needed to examine treatment compliance and response rates in patients with HCV and co-morbid SUD.

The objective of this study was to assess antiviral therapy completion rates as well as end of treatment response (ETR) and SVR among patients with co-morbid SUDs served by a large VA healthcare network in order to provide empirically based data that may facilitate treatment decisions for this underserved patient population.

\section{Results \\ HCV status, antiviral therapy and demographic information}

Within the total sample, 3.7\% $(11,012 / 297,712)$ tested positive for HCV. Of those with HCV, 7.4\% $(815 / 11,012)$ received IFN therapy during the study period (19982003). Patients on antiviral therapy were predominantly male $(96.0 \%)$, middle aged $(49.8+/-5.7$ years $)$, and Caucasian $(91.8 \%)$.

Based on SUD diagnoses, patients were categorized into two groups: 1) SUD+ Group: $16.0 \%(\mathrm{n}=47,614)$, and 2) SUD- Group: $84.0 \%(n=250,098)$. Figure 1 includes testing, infection, and treatment rates for each group. Table 1 summarizes antiviral therapy completion and response rates for patients who initiated treatment.

HCV genotypes were not available by database or medical record in $11.5 \%$ of treated cases, and these cases were not included in subsequent analyses. The SUD+ and SUDgroups did not significantly differ in terms of the percentage of patients with unavailable genotypes. 


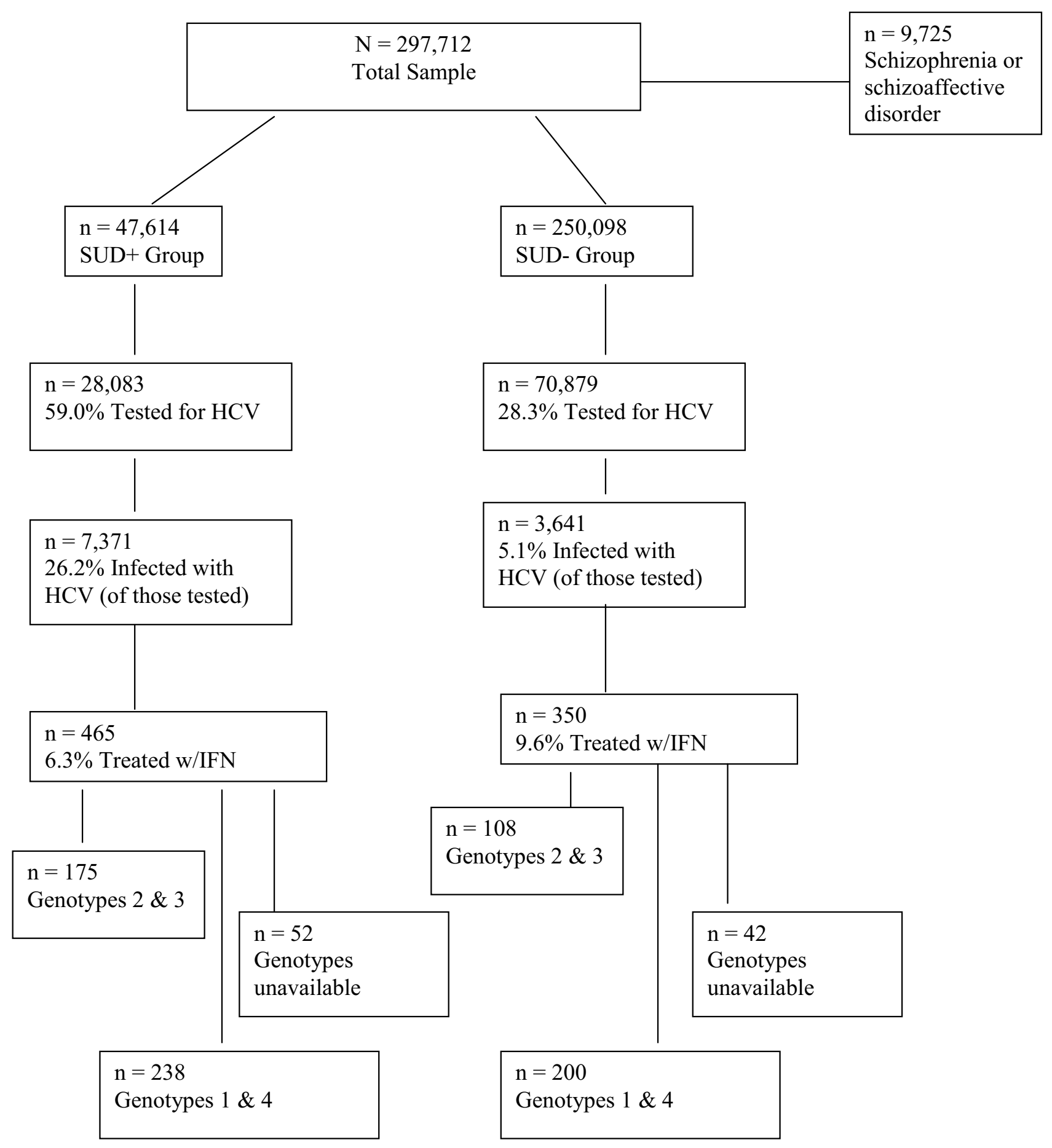

Figure I

Flow diagram of all study participants. Percentages were calculated based on the number of patients in that group divided by the number of patients in the group one step higher in the flow chart. 
Table I: Bivariate relationships between substance use disorders (SUD) and interferon (IFN) completion and response rates among veterans with available hepatitis C (HCV) genotypes

\begin{tabular}{|c|c|c|c|c|c|c|c|}
\hline & \multicolumn{2}{|c|}{ SUD- Group } & \multicolumn{2}{|c|}{ SUD+ Group } & \multirow[b]{2}{*}{ OR } & \multirow[b]{2}{*}{$95 \% \mathrm{Cl}$} & \multirow[b]{2}{*}{$\mathbf{p}$} \\
\hline & $\mathbf{N}$ & $\%$ & $\mathbf{N}$ & $\%$ & & & \\
\hline \multicolumn{8}{|c|}{ Known vs. Unknown Genotype } \\
\hline Not available & 42 & $12.0 \%$ & 52 & $11.2 \%$ & 1.08 & $0.70-1.67$ & 0.718 \\
\hline Available & 308 & $88.0 \%$ & 413 & $88.8 \%$ & & & \\
\hline \multicolumn{8}{|l|}{ Genotypes 2 \& 3} \\
\hline \multicolumn{8}{|c|}{ Completed $\geq 22$ Weeks of IFN } \\
\hline No & 29 & $26.9 \%$ & 56 & $32.0 \%$ & 0.78 & $0.46-1.33$ & 0.359 \\
\hline Yes & 79 & $73.1 \%$ & 119 & $68.0 \%$ & & & \\
\hline \multicolumn{8}{|c|}{ End of Treatment Response (ETR) } \\
\hline Not available & 8 & $7.4 \%$ & 9 & $5.1 \%$ & 1.38 & $0.51-3.74$ & 0.528 \\
\hline Available & 71 & $65.7 \%$ & 110 & $62.9 \%$ & & & \\
\hline No Response & 14 & $13.0 \%$ & 15 & $8.6 \%$ & 1.56 & $0.70-3.46$ & 0.276 \\
\hline Response & 57 & $52.8 \%$ & 95 & $54.3 \%$ & & & \\
\hline \multicolumn{8}{|c|}{ Sustained Viral Response (SVR) } \\
\hline Not available & 4 & $3.7 \%$ & 8 & $4.6 \%$ & 0.79 & $0.23-2.73$ & 0.705 \\
\hline Available & 61 & $56.5 \%$ & 96 & $54.9 \%$ & & & \\
\hline No Response & 15 & $13.9 \%$ & 24 & $13.7 \%$ & 0.98 & $0.47-2.06$ & 0.954 \\
\hline Response & 46 & $42.6 \%$ & 72 & $41.1 \%$ & & & \\
\hline \multicolumn{8}{|l|}{ Genotypes I \& 4} \\
\hline \multicolumn{8}{|c|}{ Completed $\geq 46$ Weeks of IFN } \\
\hline No & 121 & $60.5 \%$ & 143 & $60.1 \%$ & 1.02 & $0.69-1.49$ & 0.929 \\
\hline Yes & 79 & $39.5 \%$ & 95 & $39.9 \%$ & & & \\
\hline \multicolumn{8}{|c|}{ End of Treatment Response (ETR) } \\
\hline Not available & 9 & $8.3 \%$ & 19 & $10.9 \%$ & 0.51 & $0.22-1.21$ & 0.124 \\
\hline Available & 70 & $64.8 \%$ & 76 & $43.4 \%$ & & & \\
\hline No Response & 21 & $19.4 \%$ & 17 & $9.7 \%$ & 1.49 & $0.71-3.13$ & 0.294 \\
\hline Response & 49 & $45.4 \%$ & 59 & $33.7 \%$ & & & \\
\hline \multicolumn{8}{|c|}{ Sustained Viral Response (SVR) } \\
\hline Not available & 3 & $2.8 \%$ & 4 & $2.3 \%$ & 1.01 & $0.22-4.69$ & 0.991 \\
\hline Available & 55 & $50.9 \%$ & 74 & $42.3 \%$ & & & \\
\hline No Response & 23 & $21.3 \%$ & 21 & $12.0 \%$ & 1.81 & $0.87-3.79$ & 0.111 \\
\hline Response & 32 & $29.6 \%$ & 53 & $30.3 \%$ & & & \\
\hline
\end{tabular}

$\mathrm{Cl}=$ Confidence interval, ETR $=$ End of treatment response, IFN = Interferon, OR = Odds ratio, SUD = Substance use disorder, SVR $=$ Sustained viral response. ORs reflect the SUD+ Group compared with the SUD- Group. The SUD+ Group includes veterans with a history of substance use disorder. The SUD- Group includes veterans with no history of substance use disorder. Completion rates are based on all patients with available genotypes. Response rates are based on all patients with known HCV genotypes who initiated IFN therapy. Patients were considered nonresponders if they failed to clear the virus or if they were lost to follow-up (e.g., unavailable ETR or SVR).

\section{Completion and response rate for patients with genotypes} 2 and 3

The current standard of care generally recommends for patients with genotypes 2 and 3 to receive 24 weeks of antiviral therapy and for patients with genotypes 1 and 4 to receive 48 weeks of antiviral therapy. Therefore, completion and response rates were analyzed by genotype. For patients with genotypes 2 and 3, antiviral therapy completion rates were not significantly different between the SUD+ and SUD- groups. ETRs and SVRs were unavailable in the electronic medical record database in $6 \%$ and $4.2 \%$ of cases respectively; the SUD+ and SUD- groups did not differ significantly in the percentage of cases with unavailable ETRs (5.1\% vs. 7.4\%, respectively) and SVRs (4.6\% and 3.7\%, respectively). Cases with unavailable ETRs and SVRs were considered lost to follow-up and were considered non-responders in the analysis. Therefore, based on all patients who initiated antiviral therapy (intention to treat analysis), there were no significant differences between the SUD+ and SUD- groups in ETR or SVR (Table 1).

\section{Completion and response rate for patients with genotypes $I$ and 4}

For patients with genotypes 1 and 4, antiviral therapy completion rates were not significantly different between the SUD+ and SUD- groups (Table 1). ETRs and SVRs were unavailable in $6.4 \%$ and $1.6 \%$ of cases respectively; and 
again groups did not significantly differ in the percentages of unavailable ETRs (10.9\% vs. $8.3 \%$, respectively) or SVRs $(2.3 \%$ vs. $2.8 \%)$. Based on intention to treat, there were no significant differences between the SUD+ and SUD- groups in ETR or SVR (Table 1).

\section{Discussion}

Although patients with SUDs have been traditionally excluded from antiviral therapy, our data challenges attitudes that they may not be able to complete or respond to antiviral therapy. There were no significant differences between the SUD + and SUD - groups in completion of 24 weeks of antiviral therapy for genotypes 2 and 3 (73.1\%\% vs. $68.0 \%$ ), and in completion of 48 weeks of antiviral therapy for genotypes 1 and 4 (39.5\% vs. 39.9\%). Additionally, our results indicate that individuals with SUDs have similar ETRs and SVRs as those without SUDs.

To date, our study is the largest sample of HCV patients with co-morbid SUDs $(n=432)$ that describes completion rates of antiviral therapy. Our results suggest that individuals with a history of co-morbid SUD can successfully complete and respond to antiviral therapy. Furthermore, our results suggest that antiviral therapy is warranted for HCV patients with SUDs.

Historically, patients with HCV and co-morbid SUDs have been excluded from clinical trials. Consequently, IFN therapy completion and response rates for these patient groups are generally unknown. A recent national multicenter study designed to assess the role of alcohol use on HCV treatment outcomes found results similar to those presented in this paper. These investigators found that past alcohol use did not affect the ETR, SVR or discontinuation rates; however, recent alcohol use resulted in higher treatment discontinuation and lower SVR [31]. Although not within the scope of this study, it is possible that patients with co-morbid SUD may need to be more carefully monitored during antiviral therapy in order to avoid adverse effects associated with substance abuse relapse. Future studies that utilize thorough medical record review or prospective design may be able to assess the effect of antiviral therapy on relapse relates as well as what factors may contribute to improved treatment completion and response rates (e.g., co-management by mental health or addiction specialists) among patients with co-morbid SUDs.

Several factors limited the scope and generalizeability of our study. First, results are based on a retrospective review of an electronic medical record database; thus, it is unclear to what extent missing variables, inconsistencies in clinical reporting, or data entry/extraction errors may have affected results. For example, genotypes were unavailable for some patients, and the database lacked accessible ETR and SVR information for many cases. Missing genotype, ETR, and SVR data likely reflect our inability to extract this information from the electronic record when clinicians recorded this information in progress notes rather than in pre-defined database fields. Therefore, a missing ETR or SVR in the laboratory database did not necessarily indicate that a patient was lost to follow-up or that they did not respond. For this reason, response rates were calculated based only on those patients whose genotype, ETR, and SVR were available by database and may be an underestimate of the actual number of patients who achieved ETR or SVR. However, since the methodology and database limitations were equivalent across groups, our conclusion that response rates did not significantly differ between groups, likely remains valid.

Another limitation is the SUD diagnosis. Patients were categorized as having a history of SUD based on inclusion of this diagnosis in their medical records, but the accuracy of these diagnoses could not be confirmed by database. VISN 20 requires and reminds clinicians to complete only a brief substance abuse screening questionnaire with all patients annually, and it is likely that many patients with SUDs remain undiagnosed. It is possible that clinicians varied in their application of diagnostic criteria for SUDs in the electronic medical records. Yet another limitation is the electronic database extraction design, which did not allow us to determine why patients may have discontinued antiviral therapy. It is therefore unclear to what extent important variables (e.g., patient noncompliance, side effects or relapse) contributed to discontinuation or nonresponse. Finally, our veteran sample is primarily Caucasian, middle-aged, and male. Future studies could explore to what extent such demographic variables affect completion and response rates in patients with SUDs.

\section{Conclusion}

Taken together, our results are consistent with emerging research studies and treatment guidelines which suggest that antiviral therapy is feasible in patients with ongoing drug use (other than alcohol), if such patients are likely to comply with treatment and do not have other contraindications [32-34]. This conclusion is consistent with the policy proposed by Edlin et al. which states that; "decisions about the treatment of HCV infection in patients who use illicit drugs be based on individualized risk-benefit assessments, just as they are for other patients. Patient and physician should make decisions about treatment together, after a thorough discussion of the need for adherence to the treatment regimen and the risks of adverse effects and reinfection." [35] In agreement with this policy, the 2002 National Institutes of Health Consensus Statement on the Management of Hepatitis $\mathrm{C}$, the Veterans Health Administration: Treatment Recommendations for Patients with Chronic Hepatitis $\mathrm{C}$, and the 
2004 Practice Guidelines for the Management of Hepatitis $\mathrm{C}$ recommend that decisions about treatment of HCV in people with psychiatric and SUDs, including injection drug users, be made on a case-by-case basis and advise that drug use itself is not an absolute contraindication to IFN therapy for HCV [36-38].

\section{Methods}

\section{Sample and data selection}

We collected data on 307,437 patients treated between January 1998 and December 2003 at all facilities in the Veterans Integrated Service Network 20 (VISN 20) of the Veterans Healthcare Administration (VHA): 8 medical centers and 17 outpatient clinics in Alaska, Washington, Oregon, and Idaho. Data were extracted from the VISN 20 CHIPS Data Warehouse, a collection of databases from the electronic patient medical records of each facility. We collected data on demographics, psychiatric and substance use diagnoses, HCV laboratory results, and prescriptions. We did not collect data on non-veterans who had records in the system (e.g., employees or family members seen for humanitarian reasons), and so non-veterans were not included in the total sample. The Portland Veterans Affairs Medical Center Institutional Review Board approved data access for this project.

We downloaded data from the VISN 20 data warehouse into a local database using structured query language (SQL) queries, where they were organized and exported to SPSS, version 12.0 for analysis. Patients with a history of schizophrenia or schizoaffective disorder $(n=9,725 /$ 307,$437 ; 3.2 \%$ ), as defined by a Diagnostic and Statistical Manual, Fourth Edition (DSM-IV) code for either disorder in their medical record, were excluded from the total sample and subsequent analyses. Although not well supported by empirical research, it is a common clinical concern that patients with schizophrenia or schizoaffective disorder may have reduced IFN completion and response rates. Since these patients are generally over-represented in SUD populations, we excluded them from further analyses to avoid confounding influences on our results.

\section{Operational definitions \\ SUD+ group}

This group included all patients whose medical record included a history of any SUD as defined by a DSM-IV code for substance abuse or dependence (except nicotine dependence).

\section{SUD- group}

This group included patients without any documented history of SUD.

\section{HCV status}

We considered patients to have been tested for HCV if they had at least one HCV lab result in their record between 1994 and 2003 (electronic databases were not reliably extracting data from medical records prior to 1994). HCV positive patients had a positive HCV antibody test, a detectable HCV viral load by polymerase chain reaction (PCR), a positive HCV recombinant immunoblot assay (RIBA), or an identifiable HCV genotype. We classified patients with positive antibody tests but negative RIBA or PCR confirmation as false positives.

\section{Antiviral therapy}

Antiviral therapy included all types of IFN (e.g., IFN- $\alpha 2 a$, IFN- $\alpha 2 b$, IFN- $\alpha$ n 1, IFN-alfacon 1, pegylated IFN- $\alpha 2 a$, and pegylated IFN- $\alpha 2 b$ ) or combination therapy (IFN and ribavirin) prescribed to patients who were HCV positive. Patients' IFN treatment data were analyzed if records indicated that they had been prescribed at least one prescription for IFN during the study period (1998-2003).

\section{HCV genotypes}

Genotype lab results were confirmed through electronic medical record review if unavailable in the laboratory database.

\section{IFN completion}

For patients with genotypes 2 or 3 , we considered them to have completed IFN therapy if the period between their first and last IFN prescription release date, plus an additional thirty days (typically the last prescription release is for a one-month period), was greater than or equal to twenty-two weeks. For patients with genotypes 1 and 4, we considered them to have completed IFN therapy if the period between their first and last IFN prescription release date, plus thirty days, was greater than or equal to forty-six weeks.

\section{IFN response}

We defined an end of treatment response (ETR) as a negative qualitative HCV viral load or a non-detectible quantitative HCV viral load within one month of IFN therapy termination. We defined a sustained viral response (SVR) as a negative qualitative HCV viral load or a non-detectible quantitative HCV viral load at a time point, which was more than six months after IFN therapy termination. Since many patients began therapy before or after the study period (1998-2003), we reviewed lab results from 1994 through June 2006.

\section{Statistical analyses}

Odds ratio analyses were calculated to determine whether patients receiving antiviral therapy (see section 2.2 Operational Definitions) for HCV were less likely to complete or respond to antiviral therapy if they were in the SUD+ 
Group as compared with the SUD- Group. The database did not allow us to determine whether patients had been recommended six versus twelve months of IFN. However, current standard of care is to prescribe 24 weeks of IFN to patients with genotypes 2 and 3, while individuals with genotypes 1 and 4 are generally prescribed 48 weeks of IFN. Therefore, completion and response rates were analyzed separately for genotypes 2 and 3, and for genotypes 1 and 4. Patients with unknown genotypes were excluded from these analyses. Figure 1 shows how patient groups were selected for analyses.

\section{Competing interests}

The author(s) declare that they have no competing interests.

\section{Authors' contributions}

MSH developed the initial study design, coordinated the statistical analyses, and helped draft the manuscript. JML helped to draft and edit the manuscript and performed some of the statistical analyses. ADB and AL assisted with study design and performed all of the database queries and statistical analyses. PH supervised the study design, provided administrative oversight to this project and edited the final manuscript. All authors read and approved the final manuscript.

\section{Acknowledgements}

This research project was supported by internal funds. The authors thank the VA Hepatitis C Resource Center, Jane Burgess, Lawrence (Bopper) Deyton, MD, Marian Fireman, MD, David Indest, PsyD, Kenneth James, PhD, Michael Rigsby, MD, Anna Sasaki, MD, Robert Socherman, PhD, Cory Stenzel, Emily Kizer and Betsy Zucker, NP for their support and/or their help in planning this study and writing this article.

\section{References}

I. Huckans MS, Blackwell AD, Harms TA, Hauser P: Hepatitis C disease management patterns in high-risk populations: Testing, infection, and treatment rates among patients with serious mental illness and substance use disorders. Psychiatric Services 2006, 57(3):403-6.

2. Osher FC, Goldberg RW, McNary SW, Swartz MS, Essock SM, Butterfield MI, Rosenberg SD: Substance abuse and the transmission of hepatitis $\mathbf{C}$ among persons with severe mental illness. Psychiatr Serv 2003, 54:842-847.

3. el-Serag HB, Kunik M, Richardson P, Rabeneck L: Psychiatric disorders among veterans with hepatitis C infection. Gastroenterology 2002, I 23:476-482.

4. Dinwiddie SH, Shicker L, Newman T: Prevalence of hepatitis C among psychiatric patients in the public sector. Am J Psychiatry 2003, 160:172-174.

5. Patrick DM, Buxton JA, Bigham M, Mathias RG: Public health and hepatitis C. Can J Public Health 2000, 9 I SuppI I:SI8-2I, SI9-23.

6. Tortu S, Neaigus A, McMahon J, Hagen D: Hepatitis C among noninjecting drug users: a report. Subst Use Misuse 200I, 36:523-534.

7. Fried MW, Shiffman ML, Reddy KR, Smith C, Marinos G, Goncales FL Jr., Haussinger D, Diago M, Carosi G, Dhumeaux D, Craxi A, Lin A, Hoffman J, Yu J: Peginterferon alfa-2a plus ribavirin for chronic hepatitis C virus infection. N Engl J Med 2002, 347:975-982.

8. Manns MP, McHutchison JG, Gordon SC, Rustgi VK, Shiffman M, Reindollar R, Goodman ZD, Koury K, Ling M, Albrecht JK: Peginterferon alfa-2b plus ribavirin compared with interferon alfa-2b plus ribavirin for initial treatment of chronic hepatitis C: a randomised trial. Lancet 200I, 358:958-965.

9. Loftis JM, Hauser P: The phenomenology and treatment of interferon-induced depression. J Affect Disord 2004, 82: 175-190.

10. Malaguarnera M, Laurino A, Di Fazio I, Pistone G, Castorina M, Guccione N, Rampello L: Neuropsychiatric effects and type of IFNalpha in chronic hepatitis C. J Interferon Cytokine Res 200I, $21: 273-278$

II. Dieperink E, Ho SB, Thuras P, Willenbring ML: A Prospective Study of Neuropsychiatric Symptoms Associated With Interferon-alpha-2b and Ribavirin Therapy for Patients With Chronic Hepatitis C. Psychosomatics 2003, 44: 104-II 2.

12. Fried MW: Side effects of therapy of hepatitis $\mathbf{C}$ and their management. Hepatology 2002, 36:S237-44.

13. Hauser P, Khosla J, Aurora H, Laurin J, Kling MA, Hill J, Gulati M, Thornton AJ, Schultz RL, Valentine AD, Meyers CA, Howell CD: A prospective study of the incidence and open-label treatment of interferon-induced major depressive disorder in patients with hepatitis C. Mol Psychiatry 2002, 7:942-947.

14. Ho SB, Nguyen H, Tetrick LL, Opitz GA, Basara ML, Dieperink E: Influence of psychiatric diagnoses on interferon-alpha treatment for chronic hepatitis $\mathbf{C}$ in a veteran population. $\mathrm{Am} J$ Gastroenterol 2001, 96:157-164.

15. Edlin BR, Kresina TF, Raymond DB, Carden MR, Gourevitch MN, Rich JD, Cheever LW, Cargill VA: Overcoming barriers to prevention, care, and treatment of hepatitis $C$ in illicit drug users. Clin Infect Dis 2005, 40 Suppl 5:S276-85.

16. Stephenson J: Former addicts face barriers to treatment for HCV. Jama 200I, 285: I003-1005.

17. Schaefer M, Heinz A, Backmund M: Treatment of chronic hepatitis $C$ in patients with drug dependence: time to change the rules? Addiction 2004, 99: I 167-I I75.

18. Muir AJ, Provenzale D: A descriptive evaluation of eligibility for therapy among veterans with chronic hepatitis $\mathbf{C}$ virus infection. J Clin Gastroenterol 2002, 34:268-27I.

19. Cawthorne $\mathrm{CH}$, Rudat KR, Burton MS, Brown KE, Luxon BA, Janney CG, Fimmel C]: Limited success of HCV antiviral therapy in United States veterans. Am J Gastroenterol 2002, 97: I49-155.

20. Hatem C, Minello A, Bresson-Hadni S, Jooste V, Evrard P, Obert B, Lepage C, Bonithon-Kopp C, Faivre J, Monnet E, Miguet JP, Hillon P: Is the management of hepatitis $C$ patients appropriate? A population-based study. Aliment Pharmacol Ther 2005, 21:1007-10I5.

21. Sylvestre DL: Treating hepatitis $\mathbf{C}$ virus infection in active substance users. Clin Infect Dis 2005, 40 Suppl 5:S32I-4.

22. Sylvestre $D L$ : Treating hepatitis $\mathbf{C}$ in methadone maintenance patients: an interim analysis. Drug Alcohol Depend 2002, 67:117-123.

23. Dalgard O, Bjoro K, Hellum K, Myrvang B, Skaug K, Gutigard B, Bell $\mathrm{H}$ : Treatment of chronic hepatitis $C$ in injecting drug users: 5 years' follow-up. Eur Addict Res 2002, 8:45-49.

24. Backmund M, Meyer K, Von Zielonka M, Eichenlaub D: Treatment of hepatitis $\mathbf{C}$ infection in injection drug users. Hepatology 200I, 34: I88-193.

25. Robaeys G, Buntinx F: Treatment of hepatitis $\mathbf{C}$ viral infections in substance abusers. Acta Gastroenterol Belg 2005, 68:55-67.

26. Fireman M: Hepatitis $C$ treatment and substance use disorders. Psychiatric Annals 2003, 33:1-7.

27. Loguercio C, Di Pierro M, Di Marino MP, Federico A, Disalvo D Crafa E, Tuccillo C, Baldi F, del VecchioBlanco C: Drinking habits of subjects with hepatitis C virus-related chronic liver disease: prevalence and effect on clinical, virological and pathological aspects. Alcohol Alcohol 2000, 35:296-30I.

28. Ohnishi K, Matsuo S, Matsutani K, Itahashi M, Kakihara K, Suzuki K, Ito S, Fujiwara K: Interferon therapy for chronic hepatitis $\mathbf{C}$ in habitual drinkers: comparison with chronic hepatitis $\mathbf{C}$ in infrequent drinkers. Am J Gastroenterol 1996, 9 I: I 374-1379.

29. Okazaki T, Yoshihara H, Suzuki K, Yamada Y, Tsujimura T, Kawano $\mathrm{K}$, Abe $\mathrm{H}$ : Efficacy of interferon therapy in patients with chronic hepatitis C. Comparison between non-drinkers and drinkers. Scand J Gastroenterol 1994, 29:1039-1043.

30. Tabone M, Sidoli L, Laudi C, Pellegrino S, Rocca G, Della Monica P, Fracchia M, Galatola G, Molinaro GC, Arico S, Pera A: Alcohol abstinence does not offset the strong negative effect of lifetime alcohol consumption on the outcome of interferon therapy. J Viral Hepat 2002, 9:288-294. 
31. Anand BS, Currie S, Dieperink E, Bini EJ, Shen H, Ho SB, Wright T: Alcohol use and treatment of hepatitis $C$ virus: results of a national multicenter study. Gastroenterology 2006, I30:1607-1616.

32. De Bie J, Robaeys G, Buntinx F: Hepatitis C, interferon alpha and psychiatric co-morbidity in intravenous drug users (IVDU) : guidelines for clinical practice. Acta Gastroenterol Belg 2005, 68:68-80.

33. Davis GL, Rodrigue JR: Treatment of chronic hepatitis $\mathbf{C}$ in active drug users. $N$ Engl J Med 200I, 345:2I5-2I7.

34. Huber M, Weber R, Oppliger R, Vernazza P, Schmid P, Schonbucher $P$, Bertisch B, Meili D, Renner EL: Interferon alpha-2a plus ribavirin $I, 000 / I, 200 \mathrm{mg}$ versus interferon alpha-2a plus ribavirin $600 \mathrm{mg}$ for chronic hepatitis $\mathrm{C}$ infection in patients on opiate maintenance treatment: an open-label randomized multicenter trial. Infection 2005, 33:25-29.

35. Edlin BR, Seal KH, Lorvick J, Kral AH, Ciccarone DH, Moore LD, Lo $B$ : Is it justifiable to withhold treatment for hepatitis $\mathbf{C}$ from illicit-drug users? N Engl J Med 200I, 345:2II-2I5.

36. Strader DB, Wright T, Thomas DL, Seeff LB: Diagnosis, management, and treatment of hepatitis C. Hepatology 2004, 39: II47-II7I.

37. NIH: Consensus Development Conference Statement: Management of hepatitis C. Hepatology 2002, 36:S3-20.

38. VA: VA Treatment Recommendations for Patients with Chronic Hepatitis C, Version 5.0. Federal Practitioner 2003, 20:1-32.

Publish with Bio Med Central and every scientist can read your work free of charge

"BioMed Central will be the most significant development for disseminating the results of biomedical research in our lifetime. "

Sir Paul Nurse, Cancer Research UK

Your research papers will be:

- available free of charge to the entire biomedical community

- peer reviewed and published immediately upon acceptance

- cited in PubMed and archived on PubMed Central

- yours - you keep the copyright

Submit your manuscript here:

http://www.biomedcentral.com/info/publishing_adv.asp
BioMedcentral 